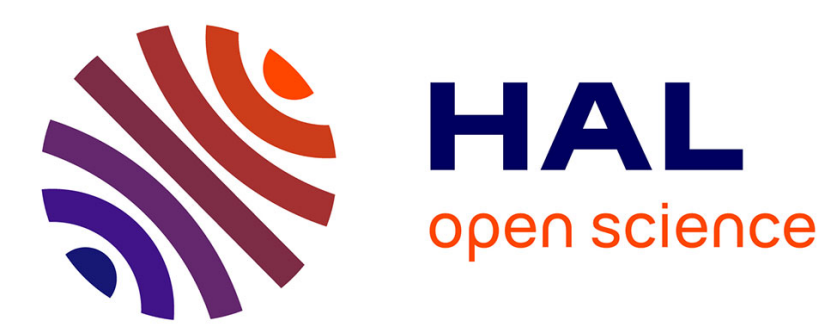

\title{
Multiple infections and the evolution of virulence
}

Samuel Alizon, Jacobus C De Roode, Yannis Michalakis

\section{To cite this version:}

Samuel Alizon, Jacobus C De Roode, Yannis Michalakis. Multiple infections and the evolution of virulence. Ecology Letters, 2013, 16 (4), pp.556-567. 10.1111/ele.12076 . hal-01567918

\section{HAL Id: hal-01567918 \\ https://hal.science/hal-01567918}

Submitted on 5 May 2018

HAL is a multi-disciplinary open access archive for the deposit and dissemination of scientific research documents, whether they are published or not. The documents may come from teaching and research institutions in France or abroad, or from public or private research centers.
L'archive ouverte pluridisciplinaire HAL, est destinée au dépôt et à la diffusion de documents scientifiques de niveau recherche, publiés ou non, émanant des établissements d'enseignement et de recherche français ou étrangers, des laboratoires publics ou privés. 


\section{REVIEW AND}

\section{SYNTHESIS Multiple infections and the evolution of virulence}

\author{
Samuel Alizon, ${ }^{1 *}$ Jacobus C. de \\ Roode $^{2}$ and Yannis Michalakis ${ }^{1}$
}

\begin{abstract}
Infections that consist of multiple parasite strains or species are common in the wild and are a major public health concern. Theory suggests that these infections have a key influence on the evolution of infectious diseases and, more specifically, on virulence evolution. However, we still lack an overall vision of the empirical support for these predictions. We argue that within-host interactions between parasites largely determine how virulence evolves and that experimental data support model predictions. Then, we explore the main limitation of the experimental study of such 'mixed infections', which is that it draws conclusions on evolutionary outcomes from studies conducted at the individual level. We also discuss differences between coinfections caused by different strains of the same species or by different species. Overall, we argue that it is possible to make sense out of the complexity inherent to multiple infections and that experimental evolution settings may provide the best opportunity to further our understanding of virulence evolution.
\end{abstract}

\section{Keywords}

Coinfection, epidemiology, kin selection, overall virulence, superinfection, transmission, vector, within-host competition.

Ecology Letters (2013) 16: 556-567
Most infections consist of multiple parasite ${ }^{\mathrm{a}}$ strains or species (see e.g. Petney \& Andrews 1998; Cox 2001; Brogden et al. 2005; Telfer et al. 2008; Balmer \& Tanner 2011; Schmid-Hempel 2011). In the case of human malaria, for instance, the majority of infected adults are simultaneously infected by more than five Plasmodium falciparum strains (Lord et al. 1999). Multiple infections are not restricted to humans, and occur naturally in a wide range of organisms, ranging from bacteria (Turner \& Duffy 2008) to plants (Malpica et al. 2006) and animals (Sharp et al. 1997). Multiple infections have major consequences for the spread of parasites in a population (Cattadori et al. 2008; Telfer et al. 2010) as well as the decrease in host fitness due to the infection (referred to here as virulence). However, even though the importance of considering the diversity of infections is often acknowledged, our understanding of how multiple infections affect the evolution of virulence is still limited (Read \& Taylor 2001; Rigaud et al. 2010). Studying the consequences of multiple infections for virulence evolution is essentially an ecological question because the ecological mechanisms by which different parasite species or strains interact within hosts have a major impact on the subsequent evolution of virulence. Moreover, it is becoming increasingly clear that ecological feedbacks and host demography are key factors in the epidemiology and evolution of parasites.

Considering that a host is infected by more than one parasite genotype introduces potential confusions because the virulence experienced by the multiply infected host (which we refer to as the 'overall virulence') is the result of the interaction between the genotypes of all the coinfecting parasites and of the host (Seppälä et al. 2009, 2012). Depending on the biological system, overall virulence can be higher than the virulence of the most virulent parasite, lower than the virulence of the least virulent parasite, or take some intermediate value between the two. This extreme variety of outcomes (Rigaud et al. 2010) can seem daunting at first, but general patterns can be detected that are consistent with applications of ecological and evolutionary theory to within-host dynamics (Graham 2008). For instance, a meta-analysis of helminth-microparasite coinfections found that resource limitation (e.g. competition for red blood cells) between the two taxa decreases the microparasite population size, whereas suppression of inflammatory immune responses has the opposite effect (Graham 2008). Although the comparison between the virulence of parasites in single infections and their overall virulence in multiple infections is relevant for a number of issues (e.g. to understand the mechanisms that lead to the decrease in host fitness), it is less relevant for understanding the evolution of virulence; for the latter, knowing how multiple infections affect within-host interactions and between-host transmission of each parasite strain is much more useful. This confusion is very common in the literature (Fig. 1). Throughout this review, we focus on virulence evolution.

Although multiple infections are important for parasite virulence and its evolution, many public and animal health policies still ignore long-term consequences of changes in prevalence of multiple infections (Read \& Taylor 2001; Balmer \& Tanner 2011). However, this is not surprising since we still have a limited understanding of their evolutionary consequences. Here, we review the literature on multiple infections to highlight the importance of such infections for parasite virulence. We also argue that the difference between the virulence in singly infected hosts and the virulence in coinfected
'Laboratoire MIVEGEC (UMR CNRS 5290, UR IRD 224, UM1, UM2), 911 Avenue Agropolis, B.P. 64501, 34394, Montpellier Cedex 5, France

${ }^{2}$ Biology Department, Emory University, 1510 Clifton Road, Atlanta, GA,30322, USA
*Correspondence: E-mail: samuel.alizon@montp.cnrs.fr

aThe term 'parasite' is used throughout this review to refer to any micro- or macro-parasites (i.e. from viruses to worms), as it is commonly done in ecology and evolution. 


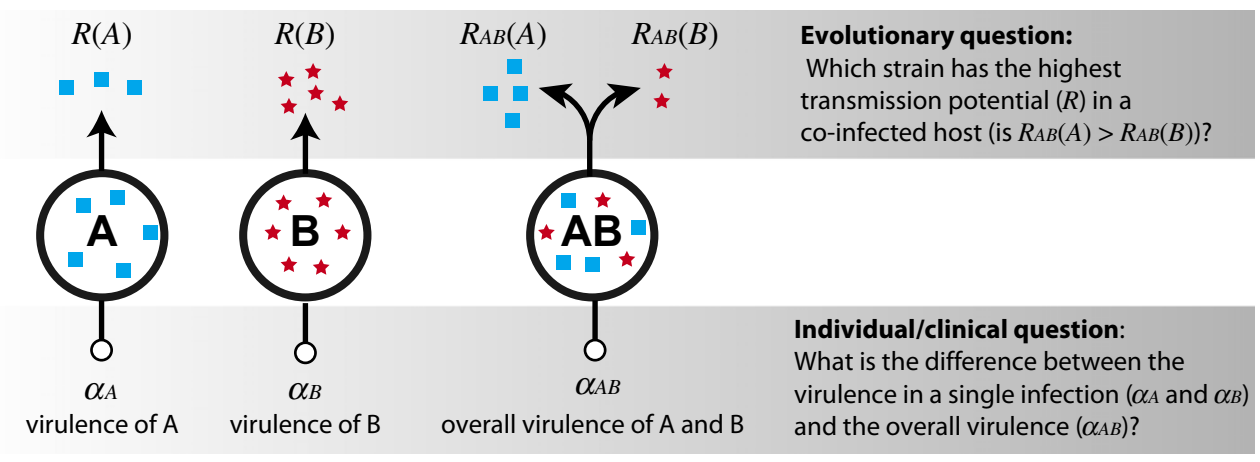

Figure 1 Difference between virulence evolution and overall virulence. Although the comparison between the virulence of parasites in single infections and the overall virulence they cause when coinfecting a host is relevant for a number of issues (e.g. to understand the mechanisms underlying virulence), it is less relevant to understand the evolution of virulence; for the latter, knowing how multiple infections affect the duration of the infection and the between-host transmission of each parasite strain is much more useful.

hosts (i.e. the overall virulence) cannot be used to predict virulence evolution. Then, we discuss theoretical and empirical studies that focus on within-host interactions and their consequences for parasite evolution. Finally, we discuss perspectives for future research in this area, making suggestions for empirical studies that can advance our understanding of the evolutionary consequences of multiple infections. Our overall goal is to review studies, identify potential generalisations and propose future approaches on the effect of multiple infections on the evolution of the virulence of infectious diseases. Although virulence may be a composite trait of host genes, parasite genes and the environment, we focus on virulence as a parasite trait in this review. This enables us to explore the consequences of multiple infections on parasite evolution.

\section{VIRULENCE EVOLUTION}

By definition, parasites cause harm to their hosts by decreasing their fitness, and this harm is usually referred to as virulence (Read 1994). Evolutionary biologists have long been puzzled by the fact that parasites harm their hosts because they depend on them for their survival. 'Conventional wisdom', as May \& Anderson (1983) called it, used to say that parasite virulence is transitory and that, given enough time, all parasites would evolve to become commensalistic or mutualistic to their hosts. Recent research has questioned this conventional wisdom and enhanced our understanding of why parasites could evolve to maintain virulence. Adaptive explanations of a non-zero level of virulence consider the balance between the effects of within-host and between-host processes on parasite fitness.

A parasite may affect host fitness by modifying host fecundity, host survival or both. Not all components, however, will be relevant to the evolution of virulence. This will depend on the parasite's life cycle. For example, if a parasite is not transmitted vertically (i.e. from parent to offspring), a decrease in host fecundity will not affect parasite fitness at the epidemiological level. For this reason, in most models, which assume parasites are not transmitted vertically, virulence is considered to be the increase in host mortality rate due to the infection and all potential effects on host fecundity are ignored. Obviously, if one is interested in the evolution of virulence of a vertically transmitted parasite, parasitic effects on host fecundity need to be taken into account and predictions need to be based on mathematical models which incorporate this transmission route. A further complication arises from the fact that a number of different ways to experimentally measure parasitic effects on host survival exist (e.g. case mortality, host lifespan or lethal dose), which may often be more practical than mortality rate. As shown by Day (2002), this should be a matter of great caution because theoretical predictions on the direction of virulence evolution depend on the way virulence is defined and measured. In the following, we always refer to virulence as the increase in host mortality rate because this is the way it is defined in virtually all theoretical studies.

A widespread explanation for the evolution and maintenance of parasite virulence is that virulence is adaptive because its increase is related to increased transmission to other hosts, which itself increases parasite fitness at the between-host level (Anderson \& May 1982; Ewald 1983; Fraser et al. 2007; de Roode et al. 2008). The idea is that parasites need to reach high enough numbers in their current host to ensure between-host transmission, but that such growth is detrimental to the host. As a consequence, it is often asserted that parasites cannot increase between-host transmission rates without also increasing virulence. Since virulence is the increase in host death rate due to the infection, in most of these studies which ignored vertical transmission, this generates a tradeoff between transmission and the duration of infection (assuming that the recovery rate is constant). The transmission-virulence tradeoff model is sometimes criticised but a positive correlation between virulence and transmission has been observed in several host-parasite systems (reviewed in Alizon et al. 2009). Moreover, in some cases, it has even been shown that transmission is a saturating function of virulence, implying that the highest parasite fitness is achieved at intermediate levels of virulence (Fraser et al. 2007; de Roode et al. 2008).

The adaptive nature of virulence is often envisaged in the (restrictive) case of horizontally and directly transmitted parasites. However, as soon as the parasite has other transmission routes (e.g. free-living spores, Caraco \& Wang 2008), or multiple host types (Gandon 2004), or multiple environments (Levin \& Svanborg Edén 1990), virulence in the host of interest can be traded-off against numerous traits. Although several processes can be at play at the same time (Alizon \& Michalakis 2011), we here focus on the case where the within-host parasite diversity originates from multiple infections, not from rapid within-host evolution from an initial infecting strain. 
The trade-off hypothesis is not the only hypothesis explaining why parasites harm their host; multiple infections, which we discuss in detail below, or within-host evolution (Levin \& Bull 1994) offer non-mutually exclusive alternatives. Another possibility is that the harm to the host originates from the immune response and not from the parasite host exploitation, which is referred to as immunopathology (Graham et al. 2005). For immunopathology to be relevant for parasite virulence evolution, there needs to be a correlation between the parasite host exploitation strategy and the immunopathology. This has been considered by some models (Day et al. 2007) but they tend not to include multiple infections (but see Graham 2001).

Finally, there are situations in which virulence does not affect parasite evolution. This is, for example, the case when a parasite infects a 'dead-end' host from which it will not transmit. However, it may still be possible to observe variations in virulence if the expression of virulence in the dead-end host is correlated with other components of the parasite's life cycle; this is often referred to as coincidental selection (e.g. Levin \& Bull 1994). In such dead-end hosts, one can only study the overall virulence. Indeed, it makes no sense in this case to look for the evolutionary consequences of multiple infections because there is no transmission from these hosts.

\section{OPENING THE WITHIN-HOST BLACK BOX}

\section{Model predictions}

As explained above, the trade-off hypothesis is concerned with the optimisation of parasite transmission between hosts. Considering multiple infections adds a level of selection (beyond the between-host level) acting on parasite evolution. Indeed, if there only are single infections, within-host processes can be treated as a 'black box' because the optimal host exploitation strategy at the between-host level (which is the level that matters in the long term) is the one that maximises the number of secondary infections. When different strains share a host, determining the optimal parasite trait value is less straightforward, because a strategy that is optimal at the within-host level can prove poor at the between-host level (see also Fig. 2).

Hamilton (1972) first noted that a highly diverse parasitic infection leads to a low level of relatedness among coinfecting parasites, which he thought should favour more virulent genotypes. The underlying assumption was that parasites compete for limited host resources resulting in a 'tragedy of the commons' situation (i.e. that over-exploiting the resource is an optimal strategy). This assump- tion, at the root of many theoretical models (Bremermann \& Pickering 1983; Levin \& Bull 1994; Frank 1996; Chao et al. 2000), has been shown to be biologically relevant in many cases.

However, competition for host resources is not the only way in which parasites can interact within a host (Mideo 2009). Direct interactions between parasites may involve interference competition [e.g. production by bacteria of bacteriocins that kill non-related bacteria (Massey et al. 2004)]. Parasites may also interact indirectly with each other by eliciting cross-reactive immune responses, or, more directly, by producing public goods (PG) that are required for parasite growth, for example, siderophores for bacteria (West \& Buckling 2003) or capside proteins for viruses (Turner \& Chao 2003). Public goods are not necessarily restricted to the within-cell (or even within-host) compartment; for example, transmission binding proteins in CaMV enhance between-cell transmission of cauliflower mosaic virus (Froissart et al. 2002). These interactions are listed in Table 1.

The nature of within-host interactions governs both the overall virulence of the infection as well as which genotype is selected (i.e. both the expression and the evolution of virulence). Therefore, a decrease in the relatedness between parasites coinfecting a host, which occurs when the diversity of the infection increases, can lead to opposite outcomes depending on the nature of within-host interactions (Table 1). If parasites compete for host resources, increased exploitation of host resources by a genotype increases its relative fitness and a low level of relatedness among coinfecting parasites should favour more virulent genotypes (Levin \& Bull 1994). The opposite result can occur when parasites compete over resources that they produce. In the case of bacteria producing siderophores, 'defector' strains that do not pay the cost of producing these molecules but exploit those produced by 'cooperating' strains can win the within-host competition. Then, low relatedness favours less virulent strains (Brown et al. 2002). One has to distinguish between the effect that multiple infections have on the phenotype (the overall virulence incurred by the host) and on virulence evolution (which strain is selected). For several scenarios, predicting the evolutionary effect is actually not straightforward, especially if different types of interactions occur simultaneously. For example, Choisy \& de Roode (2010) built an epidemiological model in which two parasites competed with each other over resources in the host. In the absence of any other interactions, they confirmed previous studies that such competition results in the evolution of more virulent parasites. However, when their model allowed for parasites to plastically

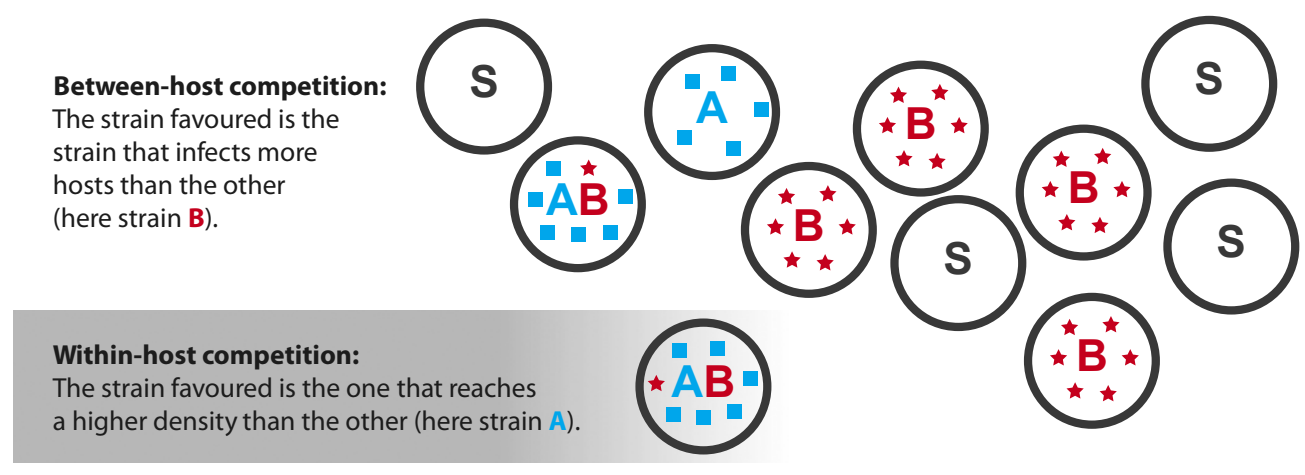

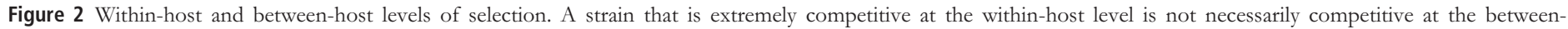

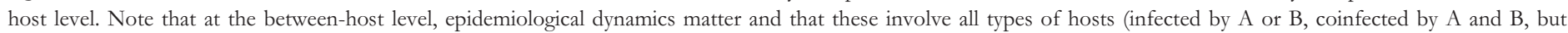
also susceptible, S). 
Table 1 Consequences of within-host interactions on the overall virulence and on parasite competition for coinfections by the same species

\begin{tabular}{|c|c|c|c|c|}
\hline Type of interaction & Overall virulence & Strain favoured & Experimental REF & Theory REF \\
\hline Competition for host resources & Higher & + & $\begin{array}{l}\text { Rodent malaria (de Roode et al. } \\
\text { 2005b) }\end{array}$ & $\begin{array}{l}\text { (Bremermann \& Pickering 1983; Levin \& Bull } \\
\text { 1994; Frank 1996; Chao et al. 2000) }\end{array}$ \\
\hline $\begin{array}{l}\text { Apparent competition via the } \\
\text { immune response }\end{array}$ & ??? & ??? & Rodent malaria (Råberg et al. 2006) & $\begin{array}{l}\text { (Brown \& Grenfell 2001; Alizon \& van Baalen } \\
\text { 2008) }\end{array}$ \\
\hline $\begin{array}{l}\text { Competition for public goods } \\
\text { produced by the parasite }\end{array}$ & Intermediate & - & $\begin{array}{l}\text { Siderophore-producing (Harrison } \\
\text { et al. 2006) }\end{array}$ & (West \& Buckling 2003) \\
\hline $\begin{array}{l}\text { Spite, that is, actively decreasing } \\
\text { the fitness of (unrelated) strains }\end{array}$ & Lower & ??? & $\begin{array}{l}\text { Bacteriocin-producing bacteria } \\
\text { (Inglis et al. 2009) }\end{array}$ & (Gardner et al. 2004) \\
\hline $\begin{array}{l}\text { Signalling, that is, production of } \\
\text { costly molecules that elicit a } \\
\text { response }\end{array}$ & $\begin{array}{l}\text { Depends on the } \\
\text { proteins elicited }\end{array}$ & - & $\begin{array}{l}\text { Quorum-sensing in bacteria } \\
\text { (Rumbaugh et al. 2009) }\end{array}$ & (Brown \& Johnstone 2001) \\
\hline Facilitation (e.g. immune depletion) & Higher & ??? & $\begin{array}{l}\text { HIV (Lawn 2004), rodent malaria } \\
\text { (Bell et al. 2006) }\end{array}$ & \\
\hline Immunopathology & Higher & ??? & See Graham et al. (2005) for a review & (Day et al. 2007) \\
\hline
\end{tabular}

For the overall virulence in multiple infections 'higher' indicates a virulence higher than the most virulent coinfecting strain; 'intermediate' indicates a virulence intermediate that of the two coinfecting strains; 'lower' indicates lower than the less virulent of the two strains; '???' indicates no known general trend; '+' (resp. '-') indicates that more (resp. less) virulent strains win the within-host competition. For further details, we refer the reader to recent reviews (Buckling \& Brockhurst 2008; Graham 2008; Mideo 2009).

increase their growth rate in mixed infections, they found that parasites evolved lower virulence. The reason for this is that parasites can optimise between-host transmission when infecting hosts singly, but can adjust their growth rates to optimally compete in mixed infections. Importantly, an experimentalist studying a mixed infection of such plastic parasites would detect increased virulence of the mixed infection relative to the respective single infections, yet evolution would result in less virulent parasites in the population. Thus, the overall virulence measured in a mixed infection would be the opposite of the evolutionary outcome. Choisy and de Roode found a similar result for when mixed infections impair the immune system of the host: again, an increased level of virulence in mixed infections accompanied an evolutionary decrease in virulence.

Many within-host models are rooted in kin selection theory (Brown et al. 2002; Buckling \& Brockhurst 2008) but others are more epidemiology oriented (e.g. Bremermann \& Pickering 1983). Kin selection models explicitly consider the between-host selection level, but they do not account for potential epidemiological feedbacks because they do not directly track the densities of the different host types (susceptible, singly infected and coinfected). The way in which within-host processes shape epidemiological parameters (virulence, transmission rate, recovery rate) affects the evolutionary outcome. However, knowing how within-host processes affect the competitive ability of a pathogen strain is not always sufficient to predict virulence evolution because the strain that wins the competition at the within-host level is not necessarily the most successful at the between-host level due to epidemiological feedbacks (van Baalen \& Sabelis 1995a; Choisy \& de Roode 2010; Alizon \& Lion 2011). For instance, within-host competition for host resources favours very virulent strains, but this increase in virulence will also lead to a decrease in the density of coinfected hosts (because singly infected hosts die before becoming coinfected), which in the end selects for less virulent strains (van Baalen \& Sabelis 1995b).

\section{Experimental data}

As argued above, the overall virulence of a multiple infection is rarely predictive of how virulence may evolve. Yet, the majority of empirical studies compare the overall virulence of a multiple infection to the virulence of each of the parasite strains in single infections, and these experiments are often misinterpreted as providing insights into virulence evolution (see also Choisy \& de Roode 2010). Overall virulence may indirectly affect virulence evolution, though, in itself, it is not informative of the evolutionary outcome. Instead, to assert whether multiple infections select for more or less virulent strains, we need to assess which of the strains (or species) that differ in their virulence win the withinhost competition and how this impacts their relative transmission success.

The best empirical evidence testing theoretical assumptions has so far come from spore-producing or vector-transmitted parasites, probably because transmission success is easier to evaluate in such systems than in directly transmitted parasites. As shown in Table 2 , the data can be divided into studies that are compatible with an evolutionary increase in virulence, which is usually due to competition for host resources or immune-mediated competition (i.e. the apparent competition between two parasite populations originating from the fact that they are both targeted by similar populations of immune cells), and studies that are compatible with an evolutionary decrease, which may occur when strains produce public goods.

The empirical results listed in Table 2 confirm theoretical predictions in the sense that when the within-host interactions are documented the observed evolutionary outcome matches that predicted by Table 1 . However, the evidence so far is not overwhelming. This current lack of empirical studies that directly address the assumptions made by theoretical models can be explained by the difficulty to meet three properties: (1) non-experimental evolution approaches rely on standing genetic variation, and thus require the availability of parasite genotypes differing in virulence in single infections, (2) it must be possible to determine the reproductive success of each genotype within a multiple infection and (3) it must be possible to assess the number of transmission events of each genotype from a multiple infection.

Experimental studies often fail on at least one of these criteria that are necessary to adequately test virulence evolution theory. They nevertheless provide valuable insights. Apart from supporting 
Table 2. Consequences of multiple infections on overall virulence and on virulence evolution

\begin{tabular}{|c|c|c|c|c|c|c|}
\hline Pathogen & Host & Virulence evolution & Overall virulence & $n$ & Interaction & Comments \\
\hline \multirow[t]{3}{*}{ Plasmodium chabaudi } & \multirow[t]{3}{*}{ Mice } & $\begin{array}{l}\text { Increase (de Roode et al. } \\
\text { 2005b; Bell et al. 2006; } \\
\text { Råberg et al. 2006) }\end{array}$ & ??? & 8 & \multirow[t]{3}{*}{$\begin{array}{l}\text { Competition for RBC, immune- } \\
\text { mediated competition }\end{array}$} & \multirow[t]{3}{*}{$\begin{array}{l}\text { Frequency-dependent effects } \\
\text { (Taylor et al. 1997) }\end{array}$} \\
\hline & & $\begin{array}{l}\text { Host-dependent (de Roode } \\
\text { et al. 2004) }\end{array}$ & ??? & 2 & & \\
\hline & & $\begin{array}{l}\text { Order of arrival-dependent } \\
\text { (de Roode et al. 2005a) }\end{array}$ & ??? & 4 & & \\
\hline Pasteuria ramosa & Daphnia magna & Increase (Ben-Ami et al. 2008) & $\begin{array}{l}\text { That of the most } \\
\text { virulent }\end{array}$ & 3 & Competition for host resources (?) & $\begin{array}{l}\text { The authors also study the effect of } \\
\text { dose and order of infection. }\end{array}$ \\
\hline $\begin{array}{l}\text { Trypanosoma brucei } \\
\text { brucei }\end{array}$ & Mice & Increase (Balmer et al. 2009) & Intermediate & 3 & $\begin{array}{l}\text { Interference competition and/or } \\
\text { immune-mediated competition (?) }\end{array}$ & $\begin{array}{l}\text { The authors do not discuss this because } \\
\text { of the limited number of comparisons. }\end{array}$ \\
\hline $\begin{array}{l}\text { Cucumber mosaic } \\
\text { virus }\end{array}$ & Tomato & Increase (Escriu et al. 2000) & Variable & 2 & ??? & \multirow[t]{2}{*}{$\begin{array}{l}\text { One of the virus strains became less } \\
\text { virulent over time }\end{array}$} \\
\hline $\begin{array}{l}\text { Nucleopolyhedro- } \\
\text { virus }\end{array}$ & Panolis flammea & $\begin{array}{l}\text { Increase but host-dependent } \\
\text { (Hodgson et al. 2004) }\end{array}$ & Higher & 2 & $\begin{array}{l}\text { Facilitation and/or immune- } \\
\text { mediated competition (?) }\end{array}$ & \\
\hline Baculovirus & $\begin{array}{l}\text { Trichoplusia ni } \\
\text { larvae }\end{array}$ & Increase (Zwart et al. 2009) & ??? & $2^{*}$ & Competition for host resources (?) & \multirow[t]{2}{*}{ The avirulent virus is genetically engineered. } \\
\hline $\begin{array}{l}\text { Post-segregational } \\
\text { killing (PSK) plasmids }\end{array}$ & E. coli bacteria & $\begin{array}{c}\text { Increase (Cooper \& } \\
\text { Heinemann 2005) }\end{array}$ & ??? & $2^{*}$ & $\begin{array}{l}\text { Interference competition: PSK } \\
\text { plasmids slow the replication of } \\
\text { psk- bacteria }\end{array}$ & \\
\hline Schistosoma mansoni & Snails & $\begin{array}{l}\text { Decrease (Gower \& Webster } \\
\text { 2005) }\end{array}$ & $\begin{array}{l}\text { Higher (Davies et al. } \\
\text { 2002) }\end{array}$ & 2 & $\begin{array}{l}\text { Interference competition and/or } \\
\text { immune-mediated competition and/ } \\
\text { or resource competition (?) }\end{array}$ & \multirow[t]{4}{*}{$\begin{array}{l}\text { The more virulent strain has a lower } \\
\text { parasite replication rate than the less } \\
\text { virulent strain }\end{array}$} \\
\hline Phage $\Phi 6$ & Psendomonas & $\begin{array}{l}\text { Decrease or frequency- } \\
\text { dependent (Turner \& } \\
\text { Chao 2003) }\end{array}$ & ??? & $2^{*}$ & PG production (capsid proteins) & \\
\hline Pseudomonas aeruginosa & Waxmoth larvae & $\begin{array}{l}\text { Decrease (Harrison } \\
\text { et al. 2006) }\end{array}$ & Intermediate & $2^{*}$ & PG production (virulence factors) & \\
\hline Pseudomonas aeruginosa & Mouse & $\begin{array}{l}\text { Decrease (Rumbaugh } \\
\text { et al. 2009) }\end{array}$ & Intermediate & $2^{*}$ & $\begin{array}{l}\text { QS and PG production (virulence } \\
\text { factors) }\end{array}$ & \\
\hline Streptoccocus pneumoniae & Mice & $\begin{array}{l}\text { Increase with } \mathrm{HI} \text { and } \\
\text { decrease without } \mathrm{HI} \\
\text { (Lysenko et al. 2010) }\end{array}$ & ??? & 2 & Immune-mediated competition & $\begin{array}{l}\text { Mixed species infection with Haemopbilus } i \\
\text { nfluenzae (HI) }\end{array}$ \\
\hline Bacillus thuringiensis & $\begin{array}{l}\text { Diamondback } \\
\text { moth }\end{array}$ & $\begin{array}{l}\text { Decrease (Garbutt } \\
\text { et al. 2011) }\end{array}$ & Decrease & $\mathrm{NA}$ & $\begin{array}{l}\text { Spite }+ \text { PG production (bacteriocins }+ \\
\text { virulence factors) }\end{array}$ & $\begin{array}{l}\text { Experimental evolution: serial passages } \\
\text { with or without coinfections }\end{array}$ \\
\hline Plasmids & E. coli bacteria & Increase (Smith 2011) & ??? & NA & & $\begin{array}{l}\text { Experimental evolution. See also comments } \\
\text { in Alizon \& Michalakis (2011) }\end{array}$ \\
\hline
\end{tabular}

*The authors vary the initial frequency in each strain.

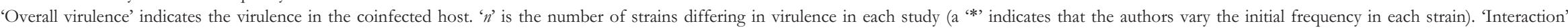
is the interaction between coinfecting parasite strains or species ('(?)' indicates a lack of definitive evidence). NA: non-applicable. 
some major theoretical assumptions, these studies have also shown that the order of infection matters and that, in many cases, the genotype that infects first is favoured (Paul et al. 2004; de Roode et al. 2005a; Ben-Ami et al. 2008). Note that this advantage could also explain why multiple infections are not observed in some hostparasite systems (e.g. infection by a phage can prevent further infections by some other phages).

Although most experimental studies have focussed on infections consisting of multiple parasite strains of the same species, virulence evolution theory can also be tested with mixed species infections. Lysenko et al. (2010) studied the influence of the presence of Haemophilus influenzae on the competition between a virulent and an avirulent strain of Streptococcus pneumoniae in mice. They found that the virulent $S$. pneumoniae loses the competition against the avirulent strain in the absence of $H$. influenzae but that it wins the competition when $H$. influenzae is present. The fact that the presence of another parasite (or even commensal) species is sufficient to reverse the outcome of the competition between parasite strains questions the generality of earlier results (e.g. Table 2).

\section{Competition experiments provide insights on within-host interactions}

Although experimental approaches can be used to test predictions of theoretical models of within-host interactions (Harrison et al. 2006; Inglis et al. 2009), the nature of within-host interactions between coinfecting parasites remains unknown for many hostparasite systems. Furthermore, several interaction processes (Table 1) may be at work at the same time and the question becomes how to identify the process driving the within-host dynamics. This is illustrated by quorum sensing, which typically combines the production of a signalling molecule and the activation of a response protein (Diggle et al. 2007), or by the combinations of microbial interactions mentioned above, for instance the simultaneous spite and PG production (Garbutt et al. 2011). So far, models tend to consider different types of within-host interactions among parasites in isolation.

Single-generation competition experiments can be informative because some patterns are more consistent with some types of interactions. For instance, if the less virulent genotype wins within-host competition and if the overall virulence is lower than the virulence of the most virulent strain, then it is reasonable to hypothesise that PG production is the major process driving within-host interactions; further experiments can be designed to actually demonstrate this. Competition experiments can thus be used as a first step to unravel the nature of within-host interactions. Of course, these experiments also inform us on virulence evolution even though, as we will see in the next section, care should be taken when interpreting the results of single-generation competition experiments.

\section{BEYOND THE WITHIN-HOST LEVEL}

\section{Serial passage experiments}

The experiments listed in Table 2 involve competition among several strains. Another type of data supporting the fact that virulence can evolve rapidly because of multiple infections comes from serial passage experiments (SPE) where the pathogen is arti- ficially passaged form one host to the next, thus relaxing selection on pathogen transmission. These studies typically find (see Ebert 1998 for a review) that virulence increases as the parasite is passaged on the same host. The fact that virulence evolves during SPE suggests that the initial infections are diverse or that they become diverse through mutation, since evolution results from selection among genetically differing variants. In SPE, virulence typically increases presumably because strains that are competitively dominant are favoured since the between-host level of selection is removed (there is no cost at killing the host rapidly). This well-documented outcome (virulence increases in SPE) probably depends on how the parasites interact within the host. For example, we do not know any examples of SPE with public goods (e.g. siderophores) producing parasites where the opposite outcome would be predicted (SPE should select for less virulent strains because, as we explained above, these are the more competitive within a host).

\section{Closing the life cycle}

To understand which parasite genotype benefits from the withinhost interaction, it is necessary to define parasite fitness. An intuitive approach is to count the number of transmission forms, when they exist (e.g. in the case of Plasmodium, one can sum up the total density of gametocytes during the infection), or the parasite load relevant to transmission in systems lacking such specialised transmission forms.

In most studies, however, it is assumed that the transmission success from the studied host is equivalent to the parasite's betweenhost fitness calculated over the whole life cycle. This assumption is much more likely to be inadequate for parasites that are not directly transmitted; the link may be confounded by trade-offs between traits expressed at the same part of the parasite life cycle or between traits expressed at different parts of the life cycle. As an example, consider a parasite that produces a free-living stage. An appropriate measure of transmission success from the host would be the number of spores released by infected hosts over the duration of an infection. However, if there is a very strong trade-off such that the number of spores produced is inversely proportional to their ability to infect a new host or to their survival in the environment, then the number of spores produced is less likely to be an accurate predictor of which parasite wins the within-host competition. Another example is vector-borne parasites, for example, Plasmodium. As mentioned above, the total gametocyte load in the vertebrate host is a straightforward estimate of the transmission success to vectors. However, if the ability to exploit the vertebrate host (and produce gametocytes) is traded-off against the ability to exploit the mosquito vector, assessing which strain benefits from coinfections becomes less straightforward. Such trade-offs will not necessarily exist across all life-cycle stages in all systems. It is, however, important to keep in mind the entire life cycle of the parasite before making definitive claims concerning the evolution of its virulence even during a part of its life cycle.

\section{Evolutionary epidemiology}

To accurately predict parasite evolution, the within- and the between-host levels need to be analysed jointly. The study of multiple infections is deeply rooted in ecology and evolution. As per- 
(a)

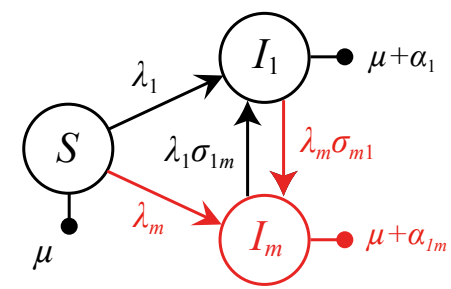

(b) Coinfections (same species)

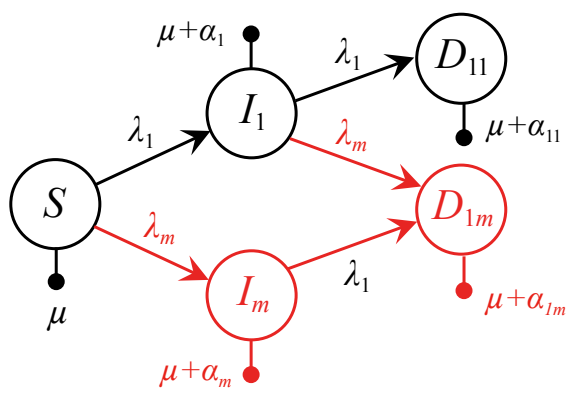

(c) Coinfections (different species)

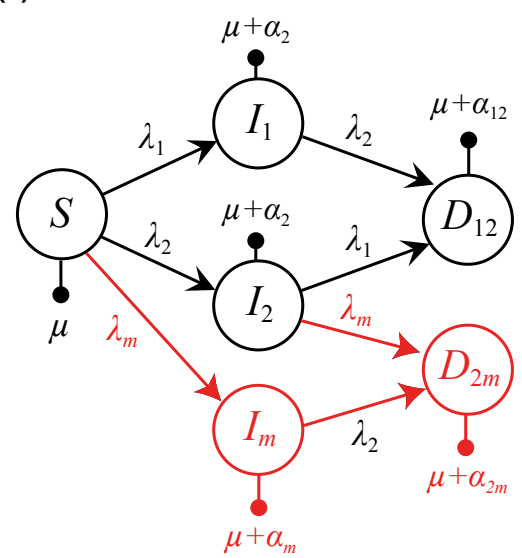

Figure 3 Evolutionary epidemiology model for (a) superinfections, (b) coinfections by parasites from the same species or (c) from different species. In black is the resident system (one strain in (a) and (b) and 2 strains, one for each species, in (c)) and in red are the host classes related to the rare mutant $(m)$. In (c) we only show an invasion analysis for a mutant strain of species $1 . \mu$ is the host base-line mortality, $\lambda_{i}$ and $\alpha_{i}$ are the force of infection and the virulence of strain $i . \alpha_{i j}$ is the diseaseinduced mortality in hosts coinfected by strains $i$ and $j$ (overall virulence) and $\sigma_{i j}$ is the rate at which strain $i$ infects a host infected by strain $j$.

ceived already by Eshel (1977), a multiple infection framework is very similar to a meta-population framework with dispersal between patches and interactions between unrelated species within a patch. Notably, these models were published before the first epidemiological models of virulence evolution with multiple infections (e.g. Levin \& Pimentel 1981). An advantage of these subdivided populations models is that they can easily allow for high diversity of infections (Gandon \& Michalakis 1999), but they only allow for limited epidemiological feedbacks. There are currently two theoretical approaches to studying the evolutionary consequences of multiple infections: the superinfection framework and the coinfection framework.

The superinfection framework assumes that upon infection of an already infected host, the most competitive strain (at the within-host level) ousts the other instantaneously (Fig. 3a). That stable (or long term) coexistence within the host never occurs can be seen as a strong assumption. For instance, even between bacteriophages lambda, for which superinfection was supposed to the rule, recent work has shown that there can be multiple integration sites, which would allow coexistence between two bacteriophages lambda (Fogg et al. 2010). In the simple setting of these models, a virulent strain has a benefit at the within-host level (because it is more adapted to take over new hosts or to resist superinfection). However, virulence incurs a cost at the between-host level: in single infections, virulent strains do not maximise the number of secondary infections because they kill their hosts too quickly. Overall, assuming that superinfections occur and that more virulent strains are more competitive leads to the prediction that intermediate levels of virulence are favoured. This optimal level of virulence integrates the probability for a host to be superinfected: if superinfections never occur, the optimal virulence is zero and if superinfections always occur, the optimal virulence is infinite.
The great advantage of the superinfection model lies in its simplicity: it incorporates multiple infections into a model without adding any host category (one only needs to add a transition from one type of infected host to the other). In spite of their simplicity, superinfection models already capture some of the features of more complicated models (e.g. the selection for more virulent strains if virulence confers a within-host advantage). Finally, these models are analytically tractable, which means that their behaviour is extremely well understood. They can thus help us understand the results of more complex models.

Importantly, the effect of superinfection (and of multiple infections in general) on virulence evolution is independent of the existence of a trade-off linking virulence and transmission. Indeed, even if virulence is completely independent of transmission or recovery, superinfections can lead to the selection of virulent strains if more virulent strains are more competitive at the withinhost level (Alizon \& Michalakis 2011). Of course, it is also possible to combine the trade-off model and superinfections (Nowak \& May 1994; Gandon et al. 2002; Alizon \& Michalakis 2011).

As most of the time parasite strains co-exist for at least some time within the host, an alternative approach to the superinfection framework is the 'coinfection' framework (Fig. 3b,c), in which parasite coexistence within a host is assumed to last until the host dies or recovers (van Baalen \& Sabelis 1995a; May \& Nowak 1995). In most coinfection models, competitive exclusion cannot occur in coinfected hosts, which is one of the reasons why these models have been argued to be unrealistic. However, this competitive exclusion could be modelled, for example, by allowing for partial recovery (i.e. clearance of only one of the strains) and having this clearance rate be a function of strain within-host competitive ability. Alizon \& van Baalen (2008) also used a nested model, which combines 
within-host and epidemiological dynamics, to account for this strain replacement in coinfected hosts. They showed that this can alter the evolutionary outcome of the model by generating an 'evolutionary branching' in the parasite population, that is, the evolution of a dimorphic parasite population with one morph being adapted to infecting susceptible hosts and another morph adapted to infecting already infected hosts. Note that similar results have been obtained in superinfection models (Gandon et al. 2002). Coombs et al. (2007) also built such a nested model for a case where the connecting parasites are always cotransmitted. They find the classical result that the strain that has the optimal within-host strategy can be outcompeted at the between-host level, and they also show that allowing for mutation from one strain to the other strongly affects the behaviour of the model since all hosts are infected by the two strains.

Coinfection models are more difficult to analyse than superinfection models (they always require at least an additional host class), but they allow incorporating more biology. Moreover, accounting for coinfected hosts incites us to specifying the transmission rate from each of the coinfecting strains and the overall virulence. One of the results of these models is that the type of overall virulence can indirectly affect the optimal level of virulence (Alizon 2008). This is where the knowledge from experimental studies (Table 2) proves to be crucial. Also, explicitly tracking the prevalence of coinfected hosts is useful: the outcome of within-host competition is obviously unimportant if coinfected hosts are extremely rare, but it becomes crucial if coinfected hosts are common. We already mentioned the fact that the increase in virulence due to within-host competition should lead to a decrease in the prevalence of coinfections and hence to a decrease in virulence (van Baalen \& Sabelis 1995b). As a result of this feedback, the strains should evolve towards an intermediate level of virulence. Depending on the sensitivity of hosts to coinfection, that is, their probability to be infected when they are already infected (Alizon \& van Baalen 2008), strains will adapt more to the within-host level (which for this type of within-host interactions means more virulent) or to the between-host level (less virulent). More recently, Alizon \& Lion (2011) showed using the model of bacteria producing siderophores that epidemiological feedbacks can alter the direction of virulence evolution. Indeed, classical models that focus on the within-host level predict that increased levels of coinfection should select for less virulent strains (i.e. 'cheating' strains that do not produce siderophores). When epidemiological feedbacks are accounted for, the relationship between prevalence of coinfections and virulence can become nonmonotonic such that, at first, increasing the average number of strains per host selects for more virulent strains but beyond a given number of strains further increasing the number of strains actually favours less virulent strains.

Importantly, there are two main families of coinfection models that make different assumptions regarding the differences between coinfecting strains. For clarity, we refer to these as coinfections by different strains of the same species (van Baalen \& Sabelis 1995a) and coinfections between strains from different parasite species (Choisy \& de Roode 2010). The latter model makes no assumption about the resemblance between the coinfecting strains. This is why it assumes two resident strains [one for each species, (Fig. 3c)]. The downside of the 'two species' coinfection model is that it requires numerical approaches because equilibrium densities of the resident state cannot be computed analytically. Conversely, the 'one species' model assumes that the coinfecting strains are very similar. In a way, this model can be seen as a version of the two-species model in which the two species have so few differences that all the hosts singly infected by one of the two resident strains can be grouped in the same class. This 'one species' evolutionary epidemiology model can seem somehow counter-intuitive because it requires to account for hosts infected twice by the resident strain. Indeed, as first noticed by van Baalen \& Sabelis (1995a), without this additional category, the mutant strain always has an advantage because of its rarity, which means it will always grow (see also Alizon 2008; Lipsitch et al. 2009). If one assumes that hosts coinfected by the same strain are identical to singly infected hosts (except that they cannot be infected), which makes sense for micro-parasites, then this assumption becomes less important.

Overall, the 'two-species' model is never wrong but it can be unnecessarily complicated. More analyses are needed to determine the usefulness of this model, but the most promising ideas seem to apply it to specific diseases, especially if the two species are known to interact within the host in a specific way (e.g. if one species facilitates the infection by another species).

\section{Experimental evolution}

As pointed out above, the particular mechanisms by which parasites interact within hosts can have important effects on the evolution of parasite virulence. What is currently less clear is how virulence evolves when multiple interactions occur at the same time, as is likely to be the case in natural systems. Thus, experiments, which utilise natural systems and make no assumptions about which processes occur, are necessary to determine how multiple infections drive the evolution of virulence. Furthermore, as we have explained, single generation experiments are useful for determining the processes by which parasites interact, but do not lead to firm conclusions about the direction or magnitude of the evolution or virulence. Therefore, we suggest that experimental evolution studies are the best way to determine how multiple infections drive the evolution of virulence.

The first step in such an approach would be to find a suitable host-parasite system. The second step would be to determine whether parasite isolates with variable levels of virulence are available. An advantage of using an experimental evolution approach is that distinguishing between strains on the basis of molecular, immunological or morphological markers is not necessary (one can compare the evolutionary outcomes obtained with or without coinfections). Since different parasite species are often easier to distinguish than different strains of the same species, studying multiple infections by different species is likely to be easier than those by multiple strains of the same species. Furthermore, accurately controlling for the prevalence of confections by parasites from the same species seems unfeasible (one can vary host density to vary the prevalence of coinfections but this is not a precise control and it might introduce complex epidemiological feedbacks). The third step would be to determine how the variable strains or species interact within the host: for example, do the strains compete over host resources, or is there public good production? This third step is not actually mandatory since the result of the experimental evolution is interesting in itself.

Although this outline for setting up an experimental evolution approach is simplified, it is not unrealistic. In fact, Garbutt et al. 
(2011) studied the evolution of the bacterial insect parasite Bacillus thuringiensis $(\mathrm{Bt})$ in SPE. They showed that when a pathogenic $\mathrm{Bt}$ strain was passaged alone it evolved towards higher levels of virulence than when it was passaged in coinfection with a non-pathogenic Bt strain. However, it is difficult to compare the outcome of this experiment to existing theoretical models because the withinhost interactions between these two bacteria involve both PG production (virulence factors that kill the host) and interference (production of bacteriocins that kill unrelated strains), a situation not yet theoretically analysed. Furthermore, the fact that the bacteria are manually passaged from one host to the next also affects virulence evolution in a way that is not included in classical models (Ebert 1998). Completing the life cycle does not necessarily address the concern about the importance of epidemiological feedbacks, and in particular the fact that not all hosts are coinfected (or even infected). Again, a solution could come from an experimental approach where the infections would occur 'naturally'. The study discussed above used SPE but letting the parasite evolve in a host population would allow for epidemiological dynamics. These dynamics might differ from those observed in vivo, especially if new susceptible hosts are added regularly to the medium. However, any dynamics are better than no dynamics because it is important that hosts do not all have the same state. Furthermore, it is also possible to build adequate epidemiological models that capture this setting.

\section{Species or strains?}

Does it matter whether parasites competing within the same host belong to different species or are different genotypes of the same species? In both cases, we are interested in the evolution of virulence within a species, so the question addresses the issue of whether selection on virulence through coinfection is exerted by other genotypes of the same species, or by genotypes of another species.

Intuitively, different parasite species are more likely to differ than different genotypes of the same species in many respects: the types of resources they extract from the host, the types of host tissues they exploit, the type of immune defences they elicit and the extent to which these immune defenses cross-react, the transmission mode, the way virulence is linked to between-hosts transmission. It is thus probable that the within-host mechanisms involved differ between the two cases. However, precisely what matters most is knowing the nature and magnitude of the effects of the different mechanisms in operation.

For clarity, in the two-'species' model, the two competing genotypes might very well belong to the same species. In fact, if the within-host interactions are the same, the evolutionary stable strategy (ESS) for the parasite in a one-'species' model should be identical to the co-ESS reached by the two 'species' in a two-'species' model. One of the reasons for this lack of difference in the predictions (and also this interchangeability of the terms strains or species in the model) is that models of virulence evolution typically assume that parasites are asexual. This state probably partly reflects the fact that we are clueless about the genetic basis of virulence (sensu decrease of host fitness), one of the reasons being that it depends on interactions between the host genotype, the genotype of both parasites and the environment (i.e. $G \times G \times G \times E$ interactions, Seppälä et al. 2009, 2012), and therefore rather than building very complicated models assuming a polygenic genetic basis of virulence ungrounded on empirical results it is better to build simple models. Moreover, even though processes, such as recombination, for example, in the case of Plasmodium (Conway et al. 1999) or HIV (Fang et al. 2004), or reassortment, for example, in the case of influenza viruses (McHardy \& Adams 2009), are clearly involved in the generation of parasite diversity, there is no clear theory as to how these processes would matter to virulence, for example, in all the examples listed in Table 1 . The three eukaryotes listed in Table 1 have one host where they are asexual and another host where they are sexual, and all the studies reported in the table focussed on the 'asexual' host.

In the end, the choice of the framework depends on our ability to distinguish different genotypes in the parasite population and/or to the knowledge of within-host interactions. If the two parasites are indistinguishable, we can use a 'two species' coinfection model but since there would be no support for differences between the 'species', all singly infected hosts would behave in the same way and we would de facto end up with a one-species model. Of course, the research goal matters and even if there are no known differences among the parasites, the two-species model can be used to explore potential consequences of differences between parasite species.

When performing experiments, the key point is the ability to sort different genotypes, because it allows comparing treatments with or without coinfections. The knowledge of within-host interactions in coinfections is also important but without the ability to sort out genotypes, it becomes difficult to have a 'reference' treatment. There are some possibilities, such as varying the input of susceptible hosts to vary the average number of genotypes per host, but this also generates complicated epidemiological feedbacks (Day \& Gandon 2007).

\section{PERSPECTIVES}

The vast diversity of possible interactions for multiple infections may seem overwhelming (Rigaud et al. 2010). However, we think that experiments can help us identify general patterns among the diverse ways that multiple infections affect parasite evolution. Competition experiments that attempt to determine if more or less virulent genotypes benefit from within-host competition and that estimate the resulting overall virulence can either corroborate existing knowledge about within-host interactions or guide future research designed at understanding within-host processes.

Another variation of the simple experimental evolution approach would be to use different types of hosts that vary in their levels of immunity. Higher levels of immunity may alter the selective pressure on virulence (Mackinnon \& Read 2004), and in principle the recovery rate of hosts will importantly affect parasite fitness in a multiple infection, especially when there is cross-immunity. To incorporate such biological realism into evolutionary experiments, one may consider (partly) immunising groups of hosts to either of the parasites used in the experiment and then expose these to single or multiple infections for several generations. Although this may not directly answer the question of how transitory dynamics affect immunity and hence subsequent dynamics, this approach would help in determining the importance of cross-reactive immunity and recovery rates on the evolution of virulence. For instance, some models predict that cross-reactivity can favour more virulent para- 
sites; the idea being that such parasites elicit a stronger immune response to which they resist better than their competitors (Brown \& Grenfell 2001; Alizon \& van Baalen 2008). Other evidence suggests that the presence of a commensal can determine the outcome of the competition between virulent and avirulent strains (Lysenko et al. 2010). Therefore, it is not only the nature of the coinfecting strains that matters but also the type of environment they are put in.

This review has focussed on horizontally transmitted parasites but many parasites are vertically transmitted (from parent to offspring). Experimental evolution studies could be adapted to study such parasites. In a recent review, Vautrin \& Vavre (2009) showed that coinfections by vertically transmitted parasites are relatively frequent and hosts with multiple infections even tend to be favoured when competing with singly infected hosts. A common idea is that infections by such parasites should become avirulent (because the parasite fitness directly depends on the host fitness). However, there is still a potential for virulence to evolve even when transmission is entirely vertical, for example, if parasites manipulate host reproduction. Another possibility is that horizontally and vertically transmitted parasites infect a host together. A recent model (Jones et al. 2011) studied such infections when the vertically transmitted parasite can provide protection against the horizontally transmitted one. In this model, the presence of a protector parasite selected for more virulent horizontally transmitted parasites. The magnitude of the increase in virulence depended on the level of protection conferred and was maximised for intermediate levels of protection. Here as well, an experimental evolution study could provide a way to test this theory and thereby increase our understanding of how withinhost interactions affect the evolution of parasite virulence.

In conclusion, the question of how multiple infections affect virulence evolution calls for approaches from a variety fields. A particularly promising area of research is the multiple infections by different species because they avoid several obstacles to long-term evolutionary experiments with realistic feedbacks. Experimental evolution settings comparing evolutionary trajectories with or without multiple infections, particularly for multiple infections by different parasite species, can be used to see if the conclusions drawn at the level of a single host are still valid at the level of the whole parasite life cycle and are robust to epidemiological feedbacks. One important aspect to keep in mind is that parasites can react in a plastic way to variations in the average level of within-host relatedness (Choisy \& de Roode 2010; Mideo \& Reece 2012).

\section{CONCLUSION}

Multiple infections are common and, as shown by both theoretical and experimental studies, they strongly affect the selective pressures driving parasite evolution. We first argued that such evolutionary (inherited) effects should not be confounded with phenotypic effects on the overall virulence expressed in multiply infected hosts. We also argued that we still have an unclear view as to how exactly multiple infections affect the evolution of virulence because withinhost and between-host levels need to be studied in concert. Currently, there is a lack of experimental evolution studies on the evolution of virulence in a multiple infections context. A particularly promising area of research is the multiple infections by different species because they avoid several obstacles to long-term evolutionary experiments with realistic feedbacks. The major advantage is that working with different species allows having a control treatment without multiple infections, whereas avoiding multiple infections by similar strains from the same species is extremely difficult to achieve without deeply affecting epidemiological dynamics.

Expanding our understanding of multiple infections and virulence evolution will not only help in answering the question why parasites harm their hosts, but may also be relevant to addressing urgent public health problems. Finding original means to fight parasites in ways that leave little room for evolutionary escape is the subject of much ongoing research. One recent idea is to take advantage of cross-immunity generated during multiple infections. For instance, infection of the Aedes aegypti mosquito by Wolbachia activates immune pathways that are active against Plasmodium, dengue and chikungunya (Moreira et al. 2009). The problem is that, in addition to the inherent risk of releasing mosquitoes infected by a Wolbachia strain they have not co-evolved with, it is not clear what the evolutionary response of the other parasites (Plasmodium, dengue and chikungunya) will be. The model by Jones et al. (2011) suggests that the presence of Wolbachia could select for parasites that are more virulent to the mosquito. More generally, for vector borne diseases in order to predict virulence evolution it is important to know the correlation of virulence components across the different hosts (Gandon 2004). It is also possible that the difficulty for one parasite to infect a mosquito because of another parasite could select for parasite strains causing higher parasitaemia in humans, and thereby cause higher virulence (Michalakis \& Renaud 2009).

It is therefore crucial that we understand the long-term effects of multiple infections on parasite virulence, and not merely the effects on the overall virulence suffered by a host in a single-generation. Without such coupling of within-host processes and ecology of host and vectors, any effort to fight parasites with other parasites may be premature and lead to unforeseen and detrimental consequences.

\section{ACKNOWLEDGEMENTS}

We thank the reviewers and associate editor for their constructive comments. SA is funded by an ATIP-Avenir from CNRS and INSERM. SA and YM are funded by the CNRS and the IRD. JCdR is funded by NSF grant DEB-1019746.

\section{REFERENCES}

Alizon, S. (2008). Decreased overall virulence in co-infected hosts leads to the persistence of virulent parasites. Am. Nat., 172, E67-E79.

Alizon, S. \& van Baalen, M. (2008). Multiple infections, immune dynamics and virulence evolution. Am. Nat., 172, E150-E158.

Alizon, S., Hurford, A., Mideo, N. \& van Baalen, M. (2009). Virulence evolution and the trade-off hypothesis: history, current state of affairs and the future. J. Evol. Biol., 22, 245-259.

Alizon, S. \& Lion, S. (2011). Within-host parasite cooperation and the evolution of virulence. Proc. R. Soc. Lond. B., 278, 3738-3747.

Alizon, S. \& Michalakis, Y. (2011). The transmission-virulence trade-off and superinfection: comments to smith. Evolution, 65, 3633-3638.

Anderson, R.M. \& May, R.M. (1982). Coevolution of hosts and parasites. Parasitology, 85, 411-426.

van Baalen, M. \& Sabelis, M.W. (1995a). The dynamics of multiple infection and the evolution of virulence. Am. Nat., 146, 881-910.

van Baalen, M. \& Sabelis, M.W. (1995b). The scope for virulence management: a comment on Ewald's view on the evolution of virulence. Trends Microbiol., 3, 414-416. 
Balmer, O., Stearns, S.C., Schötzau, A. \& Brun, R. (2009). Intraspecific competition between co-infecting parasite strains enhances host survival in African trypanosomes. Ecology, 90, 3367-3378.

Balmer, O. \& Tanner, M. (2011). Prevalence and implications of multiple-strain infections. Lancet Infect. Dis., 11, 868-878.

Bell, A.S., de Roode, J.C., Sim, D. \& Read, A.F. (2006). Within-host competition in genetically diverse malaria infections: parasite virulence and competitive success. Evolution, 60, 1358-1371.

Ben-Ami, F., Mouton, L. \& Ebert, D. (2008). The effects of multiple infections on the expression and evolution of virulence in a Daphnia-endoparasite system. Evolution, 62, 1700-1711.

Bremermann, H.J. \& Pickering, J. (1983). A game-theoretical model of parasite virulence. J. Theor. Biol., 100, 411-426.

Brogden, K.A., Guthmiller, J.M. \& Taylor, C.E. (2005). Human polymicrobial infections. Lancet, 365, 253-255.

Brown, S.P. \& Grenfell, B.T. (2001). An unlikely partnership: parasites, concomitant immunity and host defence. Proc. R. Soc. Lond. B., 268, 2543-2549.

Brown, S.P., Hochberg, M.E. \& Grenfell, B.T. (2002). Does multiple infection select for raised virulence? Trends Microbiol., 10, 401-405.

Brown, S.P. \& Johnstone, R. (2001). Cooperation in the dark: signalling and collective action in quorum-sensing bacteria. Proc. R. Soc. Lond. B., 268, 961-965.

Buckling, A. \& Brockhurst, M.A. (2008). Kin selection and the evolution of virulence. Heredity, 100, 484-488.

Caraco, T. \& Wang, I.N. (2008). Free-living pathogens: life-history constraints and strain competition. J. Theor. Biol., 250, 569-579.

Cattadori, I.M., Boag, B. \& Hudson, P.J. (2008). Parasite co-infection and interaction as drivers of host heterogeneity. Int. J. Parasitol, 38, 371-380.

Chao, L., Hanley, K.A., Burch, C.L., Dahlberg, C. \& Turner, P.E. (2000). Kin selection and parasite evolution: higher and lower virulence with hard and soft selection. Q. Rev. Biol., 75, 261-275.

Choisy, M. \& de Roode, J.C. (2010). Mixed infections and the evolution of virulence: effects of resource competition, parasite plasticity and impaired host immunity. Am. Nat., 175, E105-E118.

Conway, D.J., Roper, C., Oduola, A.M., Arnot, D.E., Kremsner, P.G., Grobusch, M.P. et al. (1999). High recombination rate in natural populations of Plasmodium falciparum. Proc. Natl. Acad. Sci. USA, 96, 4506-4511.

Coombs, D., Gilchrist, M.A. \& Ball, C.L. (2007). Evaluating the importance of within-and between-host selection pressures on the evolution of chronic pathogens. Theor. Popul. Biol., 72, 576-591.

Cooper, T.F. \& Heinemann, J.A. (2005). Selection for plasmid post-segregational killing depends on multiple infection: evidence for the selection of more virulent parasites through parasite-level competition. Proc. R. Soc. Lond. B., 272, 403-410.

Cox, F.E.G. (2001). Concomitant infections, parasites and immune responses. Parasitology, 122, S23-S38.

Davies, C.M., Fairbrother, E.F. \& Webster, J.P. (2002). Mixed strain schistosome infection of snails and the evolution of parasite virulence. Parasitology, 124, 31-38.

Day, T. (2002). On the evolution of virulence and the relationship between various measures of mortality. Proc. R. Soc. Lond. B, 269, 1317-1323.

Day, T. \& Gandon, S. (2007). Applying population-genetic models in theoretical evolutionary epidemiology. Ecol. Lett., 10, 876-888.

Day, T., Graham, A. \& Read, A. (2007). Evolution of parasite virulence when host responses cause disease. Proc. R. Soc. Lond. B, 274, 2685-2692.

Diggle, S.P., Gardner, A., West, S.A. \& Griffin, A.S. (2007). Evolutionary theory of bacterial quorum sensing: when is a signal not a signal? Pbilos. Trans. $R$. Soc. Lond. B Biol. Sci., 362, 1241-1249.

Ebert, D. (1998). Experimental evolution of parasites. Science, 282, 1432-1435.

Escriu, F., Fraile, A. \& García-Arenal, F. (2000). Evolution of virulence in natural populations of the satellite RNA of cucumber mosaic virus. Phytopathology, 90, 480-485.

Eshel, I. (1977). On the founder effect and the evolution of altruistic traits: an ecogenetical approach. Theor. Popul. Biol., 11, 410-424.

Ewald, P.W. (1983). Host-parasite relations, vectors, and the evolution of disease severity. Annu. Rev. Ecol. Evol. Syst., 14, 465-485.

Fang, G., Weiser, B., Kuiken, C., Philpott, S.M., Rowland-Jones, S., Plummer, F. et al. (2004). Recombination following superinfection by HIV-1. AIDS, 18, 153-159.
Fogg, P.C.M., Allison, H.E., Saunders, J.R. \& McCarthy, A.J. (2010). Bacteriophage lambda: a paradigm revisited. J. Virol., 84, 6876-6879.

Frank, S.A. (1996). Models of parasite virulence. Q. Rev. Biol., 71, 37-78.

Fraser, C., Hollingsworth, T.D., Chapman, R., de Wolf, F. \& Hanage, W.P. (2007). Variation in HIV-1 set-point viral load: epidemiological analysis and an evolutionary hypothesis. Proc. Natl. Acad. Sci. USA, 104, 17441-17446.

Froissart, R., Michalakis, Y. \& Blanc, S. (2002). Helper componenttranscomplementation in the vector transmission of plant viruse. Phytopathology, 92, 576-579.

Gandon, S. (2004). Evolution of multihost parasites. Evolution, 58, 455-469.

Gandon, S. \& Michalakis, Y. (1999). Evolutionarily stable dispersal rate in a metapopulation with extinctions and kin competition. J. Theor. Biol., 199, 275-290.

Gandon, S., van Baalen, M. \& Jansen, V.A.A. (2002). The evolution of parasite virulence, superinfection and host resistance. Am. Nat., 159, 658-669.

Garbutt, J., Bonsall, M.B., Wright, D.J. \& Raymond, B. (2011). Antagonistic competition moderates virulence in Bacillus thuringiensis. Ecol. Lett., 14, 765-772.

Gardner, A., West, S.A. \& Buckling, A. (2004). Bacteriocins, spite and virulence. Proc. R. Soc. Lond. B., 271, 1529-1535.

Gower, C.M. \& Webster, J.P. (2005). Intraspecific competition and the evolution of virulence in a parasitic trematode. Evolution, 59, 544-553.

Graham, A.L. (2001). Use of an optimality model to solve the immunological puzzle of concomitant infection. Parasitology, 122, 61-64.

Graham, A.L. (2008). Ecological rules governing helminth-microparasite coinfection. Proc. Natl. Acad. Sci. USA, 105, 566-570.

Graham, A.L., Allen, J.E. \& Read, A.F. (2005). Evolutionary causes and consequences of immunopathology. Annu. Rev. Ecol. Evol. Syst., 36, 373-397.

Hamilton, W.D. (1972). Altruism and related phenomena, mainly in social insects. Annu. Rev. Ecol. Syst., 3, 193-232.

Harrison, F., Browning, L.E., Vos, M. \& Buckling, A. (2006). Cooperation and virulence in acute Pseudomonas aeruginosa infections. BMC Biol., 4, 21-25.

Hodgson, D.J., Hitchman, R.B., Vanbergen, A.J., Hails, R.S., Possee, R.D. \& Cory, J.S. (2004). Host ecology determines the relative fitness of virus genotypes in mixed-genotype nucleopolyhedrovirus infections. J. Evol. Biol., 17, 1018-1025.

Inglis, R.F., Gardner, A., Cornelis, P. \& Buckling, A. (2009). Spite and virulence in the bacterium Pseudomonas aeruginosa. Proc. Natt. Acad. Sci. USA, 106, 5703-5707.

Jones, E.O., White, A. \& Boots, M. (2011). The evolution of host protection by vertically transmitted parasites. Proc. Biol. Sci., 278, 863-870.

Lawn, S.D. (2004). AIDS in Africa: the impact of coinfections on the pathogenesis of HIV-1 infection. J. Infect., 48, 1-12.

Levin, B.R. \& Bull, J.J. (1994). Short-sighted evolution and the virulence of pathogenic microorganisms. Trends Microbiol., 2, 76-81.

Levin, S. \& Pimentel, D. (1981). Selection of intermediate rates of increase in parasite-host systems. Am. Nat., 117, 308-315.

Levin, B.R. \& Svanborg Edén, C. (1990). Selection and evolution of virulence in bacteria: an ecumenical excursion and modest suggestion. Parasitology, 100, S103-S115

Lipsitch, M., Colijn, C., Cohen, T., Hanage, W.P. \& Fraser, C. (2009). No coexistence for free: neutral null models for multistrain pathogens. Epidemics, $1,2-13$.

Lord, C.C., Barnard, B., Day, K., Hargrove, J.W., McNamara, J.J., Paul, R.E.L. et al. (1999). Aggregation and distribution of strains in micro-parasites. Philos. Trans. R. Soc. B., 354, 799-807.

Lysenko, E.S., Lijek, R.S., Brown, S.P. \& Weiser, J.N. (2010). Within-host competition drives selection for the capsule virulence determinant of Streptococcus pneumoniae. Curr. Biol., 20, 1222-1226.

Mackinnon, M.J. \& Read, A.F. (2004). Virulence in malaria: an evolutionary viewpoint. Philos. Trans. R. Soc. B., 359, 965-986.

Malpica, J.M., Sacristàn, S., Fraile, A. \& Garcì-Arenal, F. (2006). Association and host selectivity in multi-host pathogens. PLOS ONE, 1, e41.

Massey, R.C., Buckling, A. \& ffrench Constant, R. (2004). Interference competition and parasite virulence. Proc. R. Soc. Lond. B., 271, 785-788.

May, R.M. \& Anderson, R.M. (1983). Parasite-host coevolution. In: Coevolution (eds Futuyma, D.J. \& Slatkin, M.). Sinauer, Sunderland, MA, pp. 186-206.

May, R.M. \& Nowak, M.A. (1995). Coinfection and the evolution of parasite virulence. Proc. R. Soc. Lond. B., 261, 209-215. 
McHardy, A.C. \& Adams, B. (2009). The role of genomics in tracking the evolution of influenza a virus. PLoS Pathog., 5, e1000566.

Michalakis, Y. \& Renaud, F. (2009). Malaria: evolution in vector control. Nature, 462, 298-300.

Mideo, N. (2009). Parasite adaptations to within-host competition. Trends Parasitol., 25, 261-268.

Mideo, N. \& Reece, S.E. (2012). Plasticity in parasite phenotypes: evolutionary and ecological implications for disease. Future Microbiol., 7, 17-24.

Moreira, L.A., Iturbe-Ormaetxe, I.N., Jeffery, J.A., Lu, G., Pyke, A.T., Hedges, L.M. et al. (2009). A Wolbacbia symbiont in Aedes aegypti limits infection with dengue, Chikungunya, and Plasmodium. Cell, 139, 1268-1278.

Nowak, M.A. \& May, R.M. (1994). Superinfection and the evolution of parasite virulence. Proc. R. Soc. Lond. B, 255, 81-89.

Paul, R.E.L., Lafond, T., Müller-Graf, C.D.M., Nithiuthai, S., Brey, P.T. \& Koella, J.C. (2004). Experimental evaluation of the relationship between lethal or non-lethal virulence and transmission success in malaria parasite infections. BMC Evol. Biol., 4, 30.

Petney, T.N. \& Andrews, R.H. (1998). Multiparasite communities in animals and humans: frequency, structure and pathogenic significance. Int. J. Parasit., 28, 377-393.

Råberg, L., de Roode, J.C., Bell, A.S., Stamou, P., Gray, D. \& Read, A.F. (2006). The role of immune-mediated apparent competition in genetically diverse malaria infections. Am. Nat., 168, 41-53.

Read, A. (1994). The evolution of virulence. Trends Microbiol., 2, 73-76.

Read, A.F. \& Taylor, L.H. (2001). The ecology of genetically diverse infections. Science, 292, 1099-1102.

Rigaud, T., Perrot-Minnot, M.J. \& Brown, M.J.F. (2010). Parasite and host assemblages: embracing the reality will improve our knowledge of parasite transmission and virulence. Proc. R. Soc. Lond. B., 277, 3693-3702.

de Roode, J.C., Culleton, R., Cheesman, S.J., Carter, R. \& Read, A.F. (2004). Host heterogeneity is a determinant of competitive exclusion or coexistence in genetically diverse malaria infections. Proc. R. Soc. Lond. B., 271, 10731080 .

de Roode, J.C., Helinski, M.E.H., Anwar, M.A. \& Read, A.F. (2005a). Dynamics of multiple infection and within-host competition in genetically diverse malaria infections. Am. Nat., 166, 531-542.

de Roode, J.C., Pansini, R., Cheesman, S.J., Helinski, M.E.H., Huijben, S., Wargo, A.R. et al. (2005b). Virulence and competitive ability in genetically diverse malaria infections. Proc. Natl. Acad. Sci. USA, 102, 7624-7628.

de Roode, J.C., Yates, A.J. \& Altizer, S. (2008). Virulence-transmission trade-offs and population divergence in virulence in a naturally occurring butterfly parasite. Proc. Natl. Acad. Sci. USA, 105, 7489-7494.

Rumbaugh, K.P., Diggle, S.P., Watters, C.M., Ross-Gillespie, A., Griffin, A.S. \& West, S.A. (2009). Quorum sensing and the social evolution of bacterial virulence. Curr. Biol., 19, 341-345.
Schmid-Hempel, P. (2011). Evolutionary Parasitology: The Integrated Study of Infections, Immunology, Ecology, and Genetics. Oxford University Press, Oxford, UK.

Seppälä, O., Karvonen, A., Rellstab, C., Louhi, K.R. \& Jokela, J. (2012). Reciprocal interaction matrix reveals complex genetic and dose-dependent specificity among coinfecting parasites. Am. Nat., 180, 306-315.

Seppälä, O., Karvonen, A., Valtonen, E.T. \& Jokela, J. (2009). Interactions among co-infecting parasite species: a mechanism maintaining genetic variation in parasites? Proc. R. Soc. Lond. B, 276, 691-697.

Sharp, G.B., Kawaoka, Y., Jones, D.J., Bean, W.J., Pryor, S.P., Hinshaw, V. et al. (1997). Coinfection of wild ducks by influenza A viruses: distribution patterns and biological significance. J. Virol., 71, 6128-6135.

Smith, J. (2011). Superinfection drives virulence evolution in experimental populations of bacteria and plasmids. Evolution, 65, 831-841.

Taylor, L.H., Walliker, D. \& Read, A.F. (1997). Mixed-genotypes infections of malaria parasites: within-host dynamics and transmission success of competing clones. Proc. R. Soc. Lond. B, 264, 927-935.

Telfer, S., Birtles, R., Bennett, M., Lambin, X., Paterson, S. \& Begon, M. (2008). Parasite interactions in natural populations: insights from longitudinal data. Parasitology, 135, 767-781.

Telfer, S., Lambin, X., Birtles, R., Beldomenico, P., Burthe, S., Paterson, S. et al. (2010). Species interactions in a parasite community drive infection risk in a wildlife population. Science, 330, 243-246.

Turner, P.E. \& Chao, L. (2003). Escape from prisoner's dilemma in RNA phage ф6. Am. Nat., 161, 497-505.

Turner, P.E. \& Duffy, S. (2008). Evolutionary ecology of multiple phage adsorption and infection. In: Bacteriophage Ecology: Population Growth, Evolution, and Impact of Bacterial Viruses. Cambridge University Press, Cambridge (ed. Abedon, S.T.). Cambridge University Press, Cambridge, UK, pp. 195216.

Vautrin, E. \& Vavre, F. (2009). Interactions between vertically transmitted symbionts: cooperation or conflict? Trends Microbiol., 17, 95-99.

West, S.A. \& Buckling, A. (2003). Cooperation, virulence and siderophore production in bacterial parasites. Proc. R. Soc. Lond. B, 270, 37-44.

Zwart, M.P., der Werf, W., van Oers, M.M., Hemerik, L., van Lent, J.M.V., de Visser, J.A.G.M. et al. (2009). Mixed infections and the competitive fitness of faster-acting genetically modified viruses. Evol. Appl., 2, 209-221.

Editor, John Drake

Manuscript received 2 October 2012

First decision made 30 October 2012

Second decision made 30 November 2012

Manuscript accepted 17 December 2012 